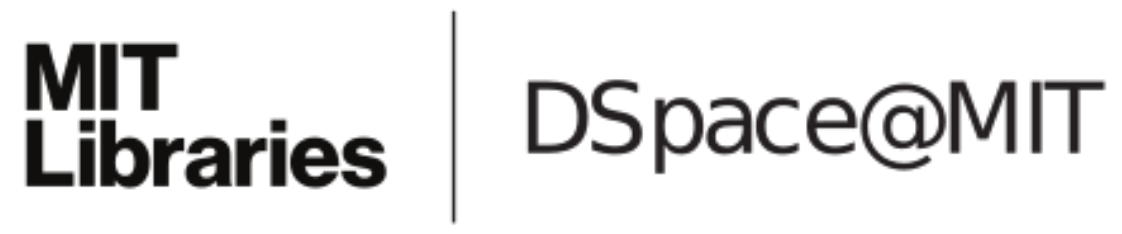

\author{
MIT Open Access Articles
}

Tagging and Targeting of Energy Efficiency Subsidies

The MIT Faculty has made this article openly available. Please share how this access benefits you. Your story matters.

Citation: Allcott, Hunt, Christopher Knittel, and Dmitry Taubinsky. "Tagging and Targeting of Energy Efficiency Subsidies." American Economic Review 105, no. 5 (May 2015): 187-91. @ 2015 American Economic Association

As Published: http://dx.doi.org/10.1257/aer.p20151008

Publisher: American Economic Association

Persistent URL: http://hdl.handle.net/1721.1/98885

Version: Final published version: final published article, as it appeared in a journal, conference proceedings, or other formally published context

Terms of Use: Article is made available in accordance with the publisher's policy and may be subject to US copyright law. Please refer to the publisher's site for terms of use. 


\title{
Tagging and Targeting of Energy Efficiency Subsidies ${ }^{\dagger}$
}

\author{
By Hunt Allcott, Christopher Knittel, And Dmitry TAubinsky
}

Corrective taxation is a common approach to addressing externalities, internalities, and other market distortions. These distortions are often heterogeneous: for example, some cars pollute more than others, and many people consume alcohol "rationally" even as present biased individuals might over-consume. Such heterogeneity raises the question of whether a corrective tax is "well-targeted": does it primarily affect individuals subject to relatively large distortions? A tax set at the average level of the distortion could actually reduce welfare if the marginal individuals were already making relatively undistorted decisions.

This paper studies the targeting of corrective subsidies for energy efficient durable goods such as air conditioners, insulation, and cars. These subsidies are justified by multiple distortions, primarily including environmental externalities, credit constraints, "landlord-tenant" information asymmetries, imperfect information, and "behavioral" biases such as inattention to energy costs (Allcott and Greenstone 2012; Gillingham, Newell, and Palmer 2009). We first argue that these distortions are heterogeneous on observables: wealthy people are less credit constrained, homeowners are unaffected by the "landlord-tenant" problem, and we show empirically that environmentalists are more attentive to energy costs and believe that energy efficient goods save more money. We then show that three major energy efficiency subsidies are

*Allcott: Department of Economics, New York University, 19 West 4th Street, New York, NY 10012, NBER, and E2e (e-mail: hunt.allcott@nyu.edu); Knittel: Sloan School of Management, Massachusetts Institute of Technology, 100 Main Street, E62-520, Cambridge, MA 02142, NBER, and E2e (e-mail: knittel@mit.edu); Taubinsky: Harvard University, Littauer Center M35, Cambridge, MA 02139, and Berkeley (e-mail: taubinsk@fas.harvard.edu).We thank Lucas Davis, Ken Gillingham, and Sendhil Mullainathan for helpful insights. We are grateful to the Sloan Foundation for financial support.

${ }^{\dagger}$ Go to http://dx.doi.org/10.1257/aer.p20151008 to visit the article page for additional materials and author disclosure statement $(\mathrm{s})$. preferentially adopted by consumers who appear to be less affected by distortions: wealthy environmentalist homeowners. However, we also show theoretically that the efficiency gains from "tagging" are larger when uniform subsidies are poorly-targeted.

\section{A Model of Optimal Subsidies and Targeting}

Our model is a minor modification of the model in Allcott and Taubinsky (forthcoming) - henceforth, AT. A unit mass of consumers make a binary choice, which in our case represents whether or not to purchase an energy efficient good such as insulation or a hybrid car. The good is produced at a constant marginal cost $c$ in a perfectly competitive market. A policymaker can set subsidy $s$, so the good's price is $p=c-s$.

The social value of purchasing the good is $v$, but consumers have perceived private valuations $\hat{v}=v-d$. The "distortion" $d$ arises from the market failures listed above, such as externalities and internalities. Positive (negative) $d$ means that consumers are distorted away from (toward) the energy efficient good. We model two distortion types $j \in\{L, H\}$, with population shares $\alpha_{j}$ and distortions $d_{L}<d_{H} \cdot 1$ Consumers purchase the good if and only if $\hat{v}>p$.

$Z$ denotes consumers' initial wealth, $F_{j}$ denotes type $j$ 's cumulative distribution of $\hat{v}$ and is assumed to be differentiable, $Q_{j}(p)$ denotes the share of type $j$ consumers who purchase, and $D(p)=\alpha_{L} Q_{L}(p)+\alpha_{H} Q_{H}(p)$ denotes total demand. The social planner maximizes $W(s)$ $=Z-R(s)+\sum_{j} \alpha_{j} \int_{x \geq c-s}\left(x+d_{j}-p\right) d F_{j}(x)$, where $R(s)$ is a lump-sum transfer that funds the subsidy.

\footnotetext{
${ }^{1}$ AT have a continuum of types and allow the distortion to depend on $\hat{v}$ and $s$, and this does not affect the welfare and subsidy formulas below. Allowing $d$ to depend on $s$ allows consumer awareness of the subsidy to affect valuations, which connects to our results in Table 2.
} 
Table 1 - Covariance of Environmentalism with Beliefs and Attention

\begin{tabular}{lcccc}
\hline \hline Dependent variable & $\begin{array}{c}\text { CFL } \\
\text { savings } \\
\text { belief } \\
(1)\end{array}$ & $\begin{array}{c}\text { Energy Star } \\
\text { savings } \\
\text { belief } \\
(2)\end{array}$ & $\begin{array}{c}\text { MPG } \\
\text { savings } \\
\text { belief } \\
(3)\end{array}$ & $\begin{array}{c}\text { Fuel cost } \\
\text { calculation } \\
\text { effort } \\
(4)\end{array}$ \\
\hline Environmentalist & 7.81 & 21.04 & -2.70 & 0.193 \\
Observations & $(3.08)^{* *}$ & $(4.80)^{* * *}$ & $(3.24)$ & $(0.112)^{*}$ \\
Dataset & 1,475 & 799 & 1,392 & 1,483 \\
\hline
\end{tabular}

Notes: Dependent variables for columns 1-3 are in percentiles, from 0-100. Dependent variable for column 4 is normalized to mean 0 , standard deviation 1 . OLS regressions with robust standard errors in parenthesis.

*** Significant at the 1 percent level.

** Significant at the 5 percent level.

* Significant at the 10 percent level.

\section{A. The Implications of a Poorly-Targeted Subsidy}

Let $\bar{d}=\sum \alpha_{j} d_{j}$ denote the population average distortion, and define "targeting" as a measure of whether high-distortion types are more responsive to the subsidy: $\tau(s)$ $\equiv \operatorname{cov}\left(d_{j},-Q_{j}^{\prime}(c-s)\right)$. We refer to a subsidy as well-targeted (poorly-targeted) if $\tau(s)$ is high (low).

Following AT, the welfare impact of a marginal increase in the subsidy $s$ is

(1) $W^{\prime}(s)=(s-\bar{d}) \cdot D^{\prime}(c-s)+\tau(s)$.

Thus, a poorly-targeted subsidy generates lower welfare gains than a well-targeted subsidy.

The first order condition for equation (1) shows that the optimal subsidy must satisfy

$$
s^{*}=\bar{d}-\frac{\tau(s)}{D^{\prime}(c-s)} .
$$

Because $D^{\prime}<0$, the optimal subsidy is increasing in $\tau(s)$. Thus, a poorly-targeted energy efficiency subsidy could optimally be small, even if the population average distortion is large.

\section{B. Tagging Is More Valuable With Poor Targeting}

We now study the gains from "tagging" (Akerlof 1978): limiting eligibility to individuals subject to greater distortions. For simplicity, we assume that the policymaker can "tag" using type-specific subsidies $s_{L}$ and $s_{H}$. Define $\Delta W$ as the welfare gains from optimal type-specific subsidies $s_{L}^{*}$ and $s_{H}^{*}$ relative to the optimal uniform subsidy $s^{*}$.

Applying equation (1) to each type's subsidy $s_{j}^{*}$ shows that $s_{L}^{*}=d_{L}$ and $s_{H}^{*}=d_{H}$. More heterogeneity in $d_{j}$ implies that $s_{L}^{*}$ and $s_{H}^{*}$ deviate more from $s^{*}$, which implies larger $\Delta W$. Proposition 1 shows that $\Delta W$ is also increasing in the absolute value of $\tau(s)$. Intuitively, $\Delta W$ is smallest when $s^{*}=\bar{d}$, which occurs when $\tau(s)$ is zero.

PROPOSITION 1: If $Q_{L}^{\prime \prime}(p), Q_{H}^{\prime \prime}(p) \approx 0$ for $p \in\left[c-s_{H}^{*}, c-s_{L}^{*}\right]$, then $\Delta W$ is increasing in $|\tau(s)|$.

\section{Empirical Results}

\section{A. Distortions Are Heterogeneous on Observables}

Columns 1-3 of Table 1 test whether environmentalists have different factual beliefs about the financial savings from energy efficient goods. Although the exact variables differ by data source, Environmentalist is a variable ranging from $0-1$ that measures individuals' self-reported level of environmentalism. Column 1 uses the AT data from the Time-Sharing Experiments for the Social Sciences (TESS) survey panel, showing that 
environmentalists are an average of 7.8 percentiles higher in the distribution of perceived cost savings from compact fluorescent lightbulbs relative to traditional incandescents. Column 2 shows that environmentalists in a phone survey by Allcott and Sweeney (2014) are an average of 21 percentiles higher in the distribution of perceived cost savings from Energy Star water heaters. Column 3 shows that environmentalists in the Vehicle Ownership and Alternatives Survey (VOAS), another TESS survey by Allcott (2013), do not have statistically different beliefs about fuel cost savings from a higher-MPG vehicle. Columns 1 and 2 suggest that environmentalists have lower $d$ due to different belief biases. Separately, these divergences are also remarkable because the survey questions elicited factual beliefs about financial savings, not opinions about the social value.

The VOAS also asks consumers how precisely they calculated fuel costs when purchasing their vehicles; we normalize this "fuel cost calculation effort" to standard deviation one. Column 4 shows that environmentalists exert 0.19 standard deviations more effort, which suggests that environmentalists have lower $d$ from inattention to energy costs.

\section{B. Characteristics of Energy Efficiency Subsidy Adopters}

Table 2 presents characteristics correlated with take-up of energy efficiency subsidies. Column 1 analyzes energy efficiency program participation at a large utility in the United States. The dependent variable is an indicator for whether the household claimed a utility-provided subsidy for energy efficient appliances, insulation, heating, ventilation, and air conditioning, or similar investments between January 2007 and April 2009. Subsidy recipients are wealthier, which suggests that the subsidies are poorly targeted to address credit constraints. Take-up is much lower at rental homes, which suggests that the subsidies are also poorly targeted toward "landlord-tenant" information asymmetries. Subsidy recipients are also more likely to have solar energy systems or voluntarily pay extra for renewable energy as part of the utility's green pricing program, suggesting that they are environmentalists who are already relatively knowledgeable about energy-related matters. We note that any uninternalized energy use externalities would optimally be addressed by setting electricity prices at social marginal cost, and this utility provides electricity from relatively low-pollution sources.

Column 2 considers the federal Residential Energy Credits, which provide income tax credits for home energy efficiency investments. 2 TESS asks all survey participants if they qualified for this credit in the past two years, and the sample combines all TESS data from AT and Allcott (2013). Column 3 considers hybrid vehicle ownership, which has been heavily subsidized by federal, state, and local governments. In these two columns, adopters are again wealthier and more environmentalist. Furthermore, the VOAS fuel cost calculation effort coefficients are positive, suggesting that more attentive (lower- $d$ ) consumers are more likely to take up, even conditional on environmentalism. 3

Two mechanisms could generate these results. First, many consumers are unaware that energy efficiency subsidies are available, and the types of consumers that are more aware of subsidies might also be more attentive to energy costs. Column 4 corroborates this using a question from the AT TESS survey, which asked consumers whether energy efficiency rebates or loans are available in their area. There were five possible responses: "Yes," "I think so, but I'm not sure," "I'm not sure at all," "I think not, but I'm not sure," and "No." Rebates or loans exist in most parts of the United States, although many consumers are unaware of this: 38 percent of consumers gave one of the latter three responses. We code responses from 1-5, with 5 being "Yes" and 1 being "No," and normalize the variable to standard deviation one. Regression results show that environmentalists are 0.248 standard deviations more likely to be aware of subsidies, which mechanically will make them more responsive to subsidies. $\underline{4}$

\footnotetext{
${ }^{2}$ Some households also qualify by purchasing household-scale solar, geothermal, and wind energy systems. See http://www.irs.gov/pub/irs-pdf/f5695.pdf for the official IRS form.

${ }^{3}$ In column 2, "fuel cost calculation effort" is coded as zero for consumers in the AT lightbulbs data, and the regressions include a separate intercept for VOAS consumers.

${ }^{4}$ We include state fixed effects to control for any potential correlation between environmentalism and subsidy availability. When we exclude these controls, the income and environmentalism point estimates are slightly more positive.
} 
Table 2-Correlates of Energy Efficiency Subsidy Take-UP

\begin{tabular}{|c|c|c|c|c|}
\hline Dependent variable & $\begin{array}{l}\text { 1(Take up } \\
\text { utility subsidy) } \\
(1)\end{array}$ & $\begin{array}{c}1 \text { (Take up } \\
\text { tax credit) } \\
(2)\end{array}$ & $\begin{array}{c}\text { 1(Own } \\
\text { hybrid) } \\
(3)\end{array}$ & $\begin{array}{c}\text { Subsidy } \\
\text { awareness } \\
\text { (4) }\end{array}$ \\
\hline 1 (Green pricing participant) & $\begin{array}{l}0.015 \\
(0.004) * * *\end{array}$ & & & \\
\hline 1(Installed solar system) & $\begin{array}{l}0.892 \\
(0.002) * * *\end{array}$ & & & \\
\hline Income (\$ millions) & $\begin{array}{l}0.543 \\
(0.066) * * *\end{array}$ & $\begin{array}{l}0.505 \\
(0.152)^{* * *}\end{array}$ & $\begin{array}{l}0.278 \\
(0.136) * *\end{array}$ & $\begin{array}{c}1.022 \\
(0.720)\end{array}$ \\
\hline 1 (Rent) & $\begin{array}{l}-0.068 \\
(0.007) * * *\end{array}$ & & & $\begin{array}{c}-0.084 \\
(0.081)\end{array}$ \\
\hline Environmentalist & & $\begin{array}{l}0.121 \\
(0.024) * * *\end{array}$ & $\begin{array}{l}0.020 \\
(0.008)^{* *}\end{array}$ & $\begin{array}{c}0.248 \\
(0.116) * *\end{array}$ \\
\hline Fuel cost calculation effort & & $\begin{array}{l}0.027 \\
(0.011)^{* *}\end{array}$ & $\begin{array}{l}0.017 \\
(0.007) * *\end{array}$ & \\
\hline Observations & 75,591 & 2,982 & 1,483 & 1,516 \\
\hline Dataset & Utility & All TESS & VOAS & Lightbulbs \\
\hline Dependent variable mean & 0.109 & 0.102 & 0.013 & 0 \\
\hline
\end{tabular}

Note: OLS regressions with robust standard errors in parentheses.

*** Significant at the 1 percent level.

**Significant at the 5 percent level.

* Significant at the 10 percent level.

When combined with the above result that environmentalists have lower $d$ from beliefs and attention, this causes poor targeting.

Second, the bottom row of Table 2 shows that the subsidies studied in columns 1-3 are applied to niche goods with small market shares, so only consumers with high perceived valuation $\hat{v}$ will tend to be marginal to a moderate subsidy. Low$d$ environmentalist consumers are more likely to be high $\hat{v}$ because they experience warm glow from conserving energy, which generates a negative covariance between $d$ and $\hat{v}$.

There is one important caveat to these results: columns 1-3 study the average adopters, not the marginal consumers. Marginal and average are equivalent if no consumer would purchase the energy efficient good without the subsidy, i.e., if $D(c)=0$. This assumption is tenuous, and direct identification of the marginal consumer would be crucial for developing this into a fully persuasive argument. (AT present one empirical design to identify the average marginal distortion.) Notwithstanding, the results do unambiguously show that these subsidies are regressive, as they preferentially accrue to wealthier consumers.

\section{Policy Implications}

There are two policy implications. First, corrective energy efficiency subsidies cannot be justified simply by the generic argument that "market distortions reduce energy efficiency investments" - we need to show that consumers affected by distortions are also affected by the subsidies. Even if these subsidies cause energy conservation, from a welfare perspective it matters who is conserving.

Second, tagging could increase the welfare gains from energy efficiency subsidies. Indeed, Proposition 1 shows that tagging becomes more valuable when existing subsidies are more poorly-targeted. Tagging could involve limiting subsidy eligibility to low-income households, rental properties, or consumers who have not yet participated in other utility programs (because previous program participation suggests being well-informed about energy). If restricting eligibility is not institutionally feasible, targeted marketing at these groups would also generate gains. Interestingly, some utilities do the opposite- they target marketing at environmentalists and previous program participants because they 
are more likely to be interested in energy efficiency. While this may be a cost-effective way to comply with existing energy efficiency regulation, our analysis shows that this may be economically inefficient.

\section{REFERENCES}

Akerlof, George A. 1978. "The Economics of 'Tagging' as Applied to the Optimal Income Tax, Welfare Programs, and Manpower Planning." American Economic Review 68 (1): 8-19.

Allcott, Hunt. 2013. "The Welfare Effects of Misperceived Product Costs: Data and Calibrations from the Automobile Market." American Economic Journal: Economic Policy 5 (3):
$30-66$.

-Allcott, Hunt, and Michael Greenstone. 2012. "Is There an Energy Efficiency Gap?" Journal of Economic Perspectives 26 (1): 3-28.

Allcott, Hunt, and Richard Sweeney. 2014. "Can Retailers Inform Consumers about Energy Costs? Evidence from a Field Experiment." National Bureau of Economic Research Working Paper 20048.

Allcott, Hunt, and Dmitry Taubinsky. Forthcoming. "Evaluating Behaviorally-Motivated Policy: Experimental Evidence from the Lightbulb Market." American Economic Review.

-Gillingham, Kenneth, Richard G. Newell, and Karen Palmer. 2009. "Energy Efficiency Economics and Policy." Annual Review of Resource Economics 1 (1): 597-620. 
This article has been cited by:

1. Hunt Allcott, Cass R. Sunstein. 2015. REGULATING INTERNALITIES. Journal of Policy Analysis and Management 34:10.1002/pam.2015.34.issue-3, 698-705. [CrossRef] 